\title{
Effect of Modified Kiln dust and a Cationic Surfactant on the Removal of Aromatic and Heavy Metal Compounds from Fuels
}

\author{
NOURA YAHYA EL MEHBAD \\ Department of Chemistry, College of Science and Arts, Najran University, \\ P. O. Box: 1988, Najran-11001, Saudi Arabia. \\ ${ }^{*}$ Corresponding author mail: faris-almansour911@ @otmail.com \\ http://dx.doi.org/10.13005/ojc/350505
}

(Received: July 28, 2019; Accepted: October 03, 2019)

\begin{abstract}
This paper aims to investigate removal of aromatic and heavy metals compounds from fuels using cement kiln dust, and a cationic surfactant. The effect of a cationic surfactant and the composition of kiln dust on the stability of fuel was studied. The optimum conditions of adsorption were investigated. The stability of fuels was improved after adsorption because of the absorption of heavy metals, which act as catalysts. The concentrations of kiln dust and additives are effective for the absorption of heteroatoms of polar and nonpolar molecules. The addition of different concentrations of the cationic surfactant to kiln dust enhances the removal of polar molecules in fuel. The relation between the efficiency of the cationic surfactant and the enhanced removal of polar molecules was established. This study suggests a new mechanism to remove polar molecules according to the structure of the additive. Several parameters that affect the performance of the removal process were investigated under all optimum conditions. A complete chemical analysis of the fuels before and after treatment was performed, and the stability of the fuel was evaluated at different conditions. The prepared additive could enhance the oil quality and is environmentally safe. The adsorption behaviour of kiln dust was investigated to find a new mechanism of its efficiency. The results confirm the role of the cationic surfactant in the purification of fuels and the effectiveness of kiln dust in improving the stability of fuels, which depend on the concentration of the cationic surfactant and the nature of the kiln dust.
\end{abstract}

Keywords: Fuel, Additives, Antioxidants, Thermal stability, Cationic surfactant, Kiln dust.

\section{INTRODUCTION}

Adsorption is a physicochemical treatment process for oil that is gaining prominence as a means to produce quality effluents. The adsorption of substrates is the first stage in many catalytic processes $^{1-4}$. The stability of fuels is affected by the thermal stability of polar compounds and the concentration of metals. Nitrogen compounds are easily adsorbed on the active sites of clays, which reduces the number of possible reactions of polar compounds. Removal of direct dyes with Cement Kiln dust has been studied, as shown in ${ }^{5}$. There is a good relation between the surface properties of the additive and their efficiency in depressing the pour point 6 . The structure of the mixed micelles is expected to be identical to that of single-component micelles. Hence, the critical micelle concentration of

This is an Open Access article licensed under a Creative Commons license: Attribution 4.0 International (CC- BY). Published by Oriental Scientific Publishing Company @ 2018

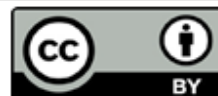


the mixed system can be theoretically deduced based on the initial composition of each component ${ }^{7-9}$. In this study, the, clay was used as an adsorbent with and without the synthesized cationic surfactant. The investigated parameters were the contact time, amount of clay, and amount of additive. A system and method for treating cement kiln dust is provided. The method includes the steps of receiving cement kiln dust (CKD) from a kiln; heating the collected CKD; forming a gas stream of vaporized metal and CKD by sufficient heating to separate at least one heavy metal from the collected CKD stream to create a cleaned CKD stream and a metal stream; providing a water soluble alkaline-earth metal polysulfide; combining the heavy metal stream with the water soluble alkaline-earth metal sulfide to create a combined stream; and removing at least a portion of one heavy metal from the combined stream.

Cement kiln dust (CKD) is generated by cement kilns worldwide. For example, CKD is generated in cement kilns during the production of cement clinker. Generally, CKD is a particulate mixture, including, amongst its constituents, partially calcined and unreacted raw feed, clinker dust and ash, enriched with alkali sulfates, halides, trace metals and other volatiles. CKD varies significantly dependent upon the specific plant process and raw materials. For reference purposes a CKD composition as reported by the Bureau of Mines* includes (Constituent $\%$ by Weight): $\mathrm{CaCO}_{3} 55.5 \%$ $\mathrm{SiO}_{2} 13.6 \% \mathrm{CaO} 8.1 \% \mathrm{~K}_{2} \mathrm{SO}_{4} 5.9 \% \mathrm{CaSO}_{4} 5.2 \%$ $\mathrm{Al}_{2} \mathrm{O}_{3} 4.5 \% \mathrm{Fe}_{2} \mathrm{O}_{3} 2.1 \% \mathrm{KCl} 1.4 \% \mathrm{MgO} 1.3 \% \mathrm{Na}_{2} \mathrm{SO}_{4}$ $1.3 \% \mathrm{KF} 0.4 \%$ Others $0.7 \%$. The properties and composition of CKD can be significantly affected by the design or operation of, or the materials used in, a cement kiln, with the result that constituent chemical and physical characteristics of CKD must be evaluated on an individual plant basis. In general, the alkaline nature of the CKD makes it a good neutralizing agent when adsorbing metals ${ }^{10}$. The advantage of this research is that we use bi-product which cause environmental pollution (kiln dust produce I million tons per year in arab countries).

This paper aims to investigate removal of aromatic and heavy metals compounds from fuels using cement kiln dust, and a cationic surfactant. The surface area of kiln dust was modified by using biodegradable cationic surfactant to enhance degree of removal of poisonous aromatic heteroatoms. At the same time, this technique has low cost in comparison with other methods such as zeolite catalyst or charcoal.

\section{EXPERIMENTAL}

\section{Feeds}

The physicochemical properties of the heavy distillate were indicated by N. Elmehbad ${ }^{11}$, however, Table 1 shows nitrogen content and metal.

Table 1: Some physicochemical properties of the heavy distillate

\begin{tabular}{lc}
\hline Properties & Base oil \\
\hline Nitrogen content (wt\%) & 5.2 \\
Metal, ppm & 300 \\
\hline
\end{tabular}

\section{Preparation of the cationic surfactant}

An equivalent mole of triethanol amine was esterified with lauric acid in xylene in the presence of $0.001 \mathrm{~g}$ of tetraethyl benzyl ammonium bromide as the catalyst, as prepared elsewhere ${ }^{6}$. After the removal of the desired amount of water, the product was purified and recrystallized by diethyl ether. The quarterisation of the product was performed with bromoacetic acid in ethanol. The product was filtered and recrystallized with purity of approximately $97 \%$. The elemental analyses of the prepared surfactant confirm its chemical structure (Table 2). [ $\left(\mathrm{HOHC}_{2} \mathrm{CH}_{2}\right)_{2} \mathrm{~N}^{+}$ $\left(\mathrm{CH}_{2} \mathrm{COOH}\right)\left(\mathrm{CH}_{2} \mathrm{CH}_{2} \mathrm{OCOC}_{11} \mathrm{H}_{23}\right] \mathrm{Br}-\mathrm{N}, \mathrm{N}$-diethanol, $\mathrm{N}$-ethyllaurate-ammonium acetate

Table 2: Elemental analysis of the prepared cationic surfactant

\begin{tabular}{lcccccccc}
\hline & \multicolumn{3}{c}{ Carbon\% } & \multicolumn{2}{c}{ Hydrogen\% } & \multicolumn{2}{c}{ Nitrogen\% } & \multicolumn{2}{c}{ Bromine } \\
\hline$\left[\left(\mathrm{HOHC}_{2} \mathrm{CH}_{2}\right)_{2} \mathrm{~N}^{+}\right.$ & Calc. & Found & Calc. & Found & Calc. & Found & Calc. & Found \\
$\left(\mathrm{CH}_{2} \mathrm{COOH}\right)\left(\mathrm{CH}_{2}\right.$ & 51.01 & 50.8 & 8.5 & 8.49 & 2.99 & 2.98 & 17.11 & 17.11 \\
$\left.\mathrm{CH}_{2} \mathrm{OCOC}{ }_{11} \mathrm{H}_{23}\right] \mathrm{Br}$ & & & & & & & & \\
\hline
\end{tabular}

\section{Mass spectroscopy}

The mass spectrum of the synthesized cationic surfactant $\mathrm{N}, \mathrm{N}$-diethanol, N-ethyllaurate- ammonium acetate illustrates a molecular ion peak at $\mathrm{m} / \mathrm{z} 444 \mathrm{~m} / \mathrm{z}$ and a base peak at $80 \mathrm{~m} / \mathrm{z}$. In addition, there is a significant peak at $255 \mathrm{~m} / \mathrm{z}$. The data of 
this spectrum confirm the chemical structure of $\left[\left(\mathrm{HOHC}_{2} \mathrm{CH}_{2}\right)_{2} \mathrm{~N}^{+}\left(\mathrm{CH}_{2} \mathrm{COOH}\right)\left(\mathrm{CH}_{2} \mathrm{CH}_{2} \mathrm{OCOC}_{11} \mathrm{H}_{23}\right)\right.$ $\mathrm{Br}$ with a purity of approximately $96 \%$.

\section{${ }^{1}$ HNMR spectroscopy}

The ${ }^{1}$ HNMR (DMSO) of the synthesized cationic surfactant. $\&=2.56$, and $=3.41, \&=7.43$ $\mathrm{ppm}$. These data confirm the chemical structure.

\section{Solvent de-waxing}

The de-waxing process was performed by using mixtures of methyl isobutyl ketone as the de-waxing solvent and $20 \mathrm{wt} \%$ ethyl acetoacetate (1:1 ratio of solvents/oil feed at a temperature of $-10^{\circ} \mathrm{C}$ ). Table 3 shows the improvement in raffinate quality, whose aromatic percentage decreased to $32 \mathrm{wt} \%$, but the value of nitrogen contents remained above $4.2 \mathrm{wt} \%$.

\section{Finishing and de-metallization by adsorption}

The raffinate oil was treated with kiln dust as the adsorbent at $50^{\circ} \mathrm{C}$. The kiln dust was activated at $105^{\circ} \mathrm{C}$ for 3 hours. Dodecane was used as the solvent in the presence of $500 \mathrm{ppm}$ of the cationic surfactant. These experiments were performed to study the effect of the amount of kiln dust on the ash and aromatic contents. The dose of kiln dust was 2, 5, $8,10 \mathrm{~g} / 100 \mathrm{ml}$ of oil and $100 \mathrm{ml}$ of $\mathrm{n}$-dodecane as the solvent at temperature $30^{\circ} \mathrm{C}$ and 500 r.p.m. agitation rate. The agitation was changed to $300,600,900$, 1100 and 1200 r.p.m. The equilibrium isotherm was studied using fixed amounts of kiln dust and stirring for two hours at $30^{\circ} \mathrm{C}$. The ash contents in oil were determined according to ASTM D 482. The metal content was analysed by atomic adsorption.

Table 3: Physicochemical properties of the raffinate after de-waxing and de-aromatization

\begin{tabular}{lcc}
\hline Properties & Raffinate oil & Test \\
\hline Density (g/ml) at $15.5{ }^{\circ} \mathrm{C}$ & 0.8935 & D. 1298 \\
Refractive index nD20 & 1.4945 & D. 1218 \\
Kinematic viscosity cst & & \\
at $40^{\circ} \mathrm{C}$ & 15.46 & D. 445 \\
at $100{ }^{\circ} \mathrm{C}$ & 27.15 & D. 455 \\
Pour point ${ }^{\circ} \mathrm{C}$ & 20 & ASTM D 97 \\
Molecular weight & 520 & GPC \\
Total paraffinic content (wr\%) & 28.4 & Urea adduction \\
Carbon residue content (wt\%) & 1.8 & ASTM D524 \\
Total aromatic (wt\%) & 34 & IP 346 \\
Nitrogen content (wt\%) & 4.2 & \\
Metal, ppm & 290 & \\
\hline
\end{tabular}

\section{RESULTS AND DISCUSSION}

Metallic compounds should be removed from oil to obtain suitable base oil for the formulation of new lubricants. The objective of this study is to evaluate kiln dust as an adsorbent to remove heavy metals and nitrogenous aromatic compounds from base oils. Furthermore, the effect of the cationic surfactant bromine salt of $\mathrm{N}, \mathrm{N}$-diethanol, N-ethyllaurateammonium acetate in the presence of kiln dust was studied. We also examined the effect of different concentrations of the additive on the degree of recovery of heavy metals. A by-pass kiln dust sample, which was used as the adsorbent, was analysed, and the composition of the constituents are shown in Table 4.

Table 4: Complete specification of the adsorbent kiln dust

\begin{tabular}{cc}
\hline Item & Composition\% \\
\hline $\mathrm{SiO}_{2}$ & 15.5 \\
$\mathrm{CaO}_{2}$ & 50.5 \\
$\mathrm{Al}_{2} \mathrm{O}_{3}$ & 4.5 \\
$\mathrm{Fe}_{2} \mathrm{O}_{3}$ & 3.5 \\
$\mathrm{MgO}$ & 0.34 \\
$\mathrm{~K}_{2} \mathrm{O}$ & 2.19 \\
$\mathrm{Na}_{2} \mathrm{O}$ & 2.68 \\
Free lime & 22.85 \\
L.O.1 & 15.6 \\
\hline
\end{tabular}

The rate of ash removal increases with an increasing rate of agitation. By increasing the agitation, the boundary layer resistance to mass transfer is reduced, and the velocity of the particles might increase (Fig. 1). These results confirm that the CAS additive enhances the removal of heavy metal in the presence of kiln dust as the adsorbent. This result can be discussed according to the physical adsorption of heavy metals by CAS on the surface of kiln dust, so adsorption occurs through surface adsorption.

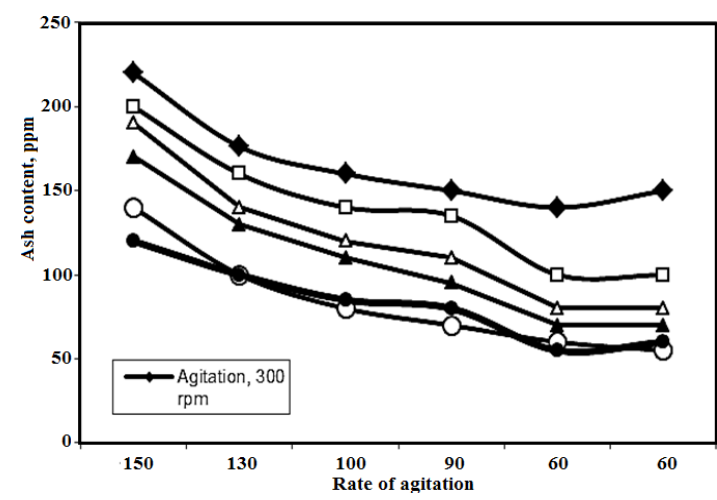

Fig. 1. Effect of the rate of agitation on the ash content (ppm) in oil raffinate in the presence of the cationic surfactant

However, the action can be enhanced by the additive CAS as shown in Fig. 2, where CAS enhances the degree of decreasing ash content without the additive. 


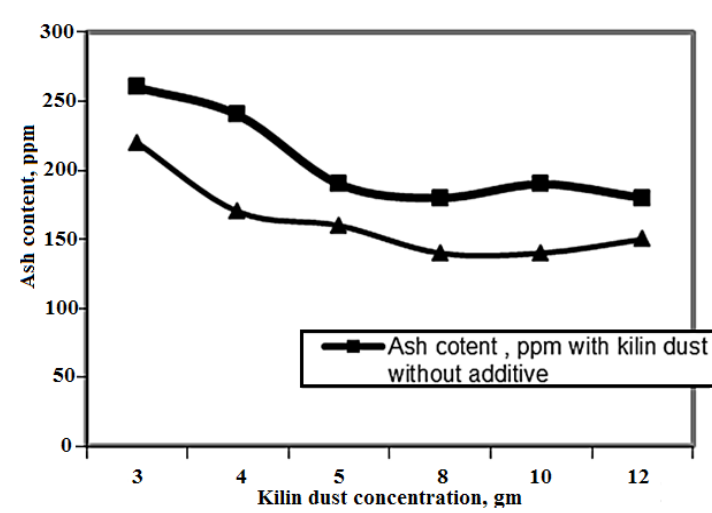

Fig. 2. Effect of $500 \mathrm{ppm}$ of cationic surfactant on the ash content (ppm) with different concentrations of kiln dust

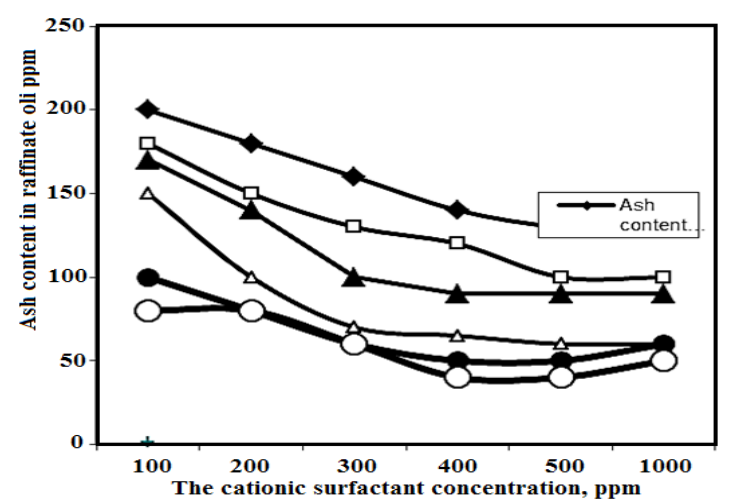

Fig. 3. Effect of the concentration of the cationic surfactant on the ash content in raffinate oil at different agitation rates

Various doses of CAS enhance the removal of ash content as shown in Fig. 3. The removal of heavy metals increases with an increase in additive concentration. The equilibrium results of decreasing ash content with increasing kiln dust and the CAS additive concentrations as shown in( Figures 1-3).

The results show that there is a synergism between zeolite and the anionic additive; the ash removal improved compared to that in the presence of the cationic additive. The optimum removal obtained was $98 \%$ with the anionic additive and $92 \%$ with the cationic additive, whereas in the case of kaolinite, it was $87 \%$ and $82 \%$. The most influential parameter that affects ash removal is the concentration of additives and time of adsorption. The results show that the viscosity increases from $30 \mathrm{cst}$ to $68 \mathrm{cst}$ for the used lube oil, but the density decreases from 912 to $900 \mathrm{~kg} / \mathrm{m}^{3}$, and the pour point decreases from -2 to $-8.5^{\circ} \mathrm{C}$. The purified oil can be reused after distillation to light naphtha and middle distillate ${ }^{11,12}$. The percentage of aromatic content in the raffinate oil decreases with a varying rate of agitation and concentration of the CAS additive in optimal conditions, as shown in Figure 4. The results show an increase in the decreasing aromatic content\% with decreasing heavy metals in raffinate oil and the formation of a layer of the adsorbate on the kiln dust surface. The author suggests that these heavy metals appear as complexes with heteroatoms such as nitrogen and sulfur. In the results, the removal efficiencies of heavy metals and aromatic using kiln dust are 15-80\% because the higher ash content indicates that the reaction between the additive and the heavy metals is weak. Increasing kiln dust concentration increases the amount of available sorption sites. Therefore, the heavy metal adsorption increases with increasing kiln dust and consequently decreases the ash content of heavy metals with a decreasing percentage of aromatic content in raffinate oil.
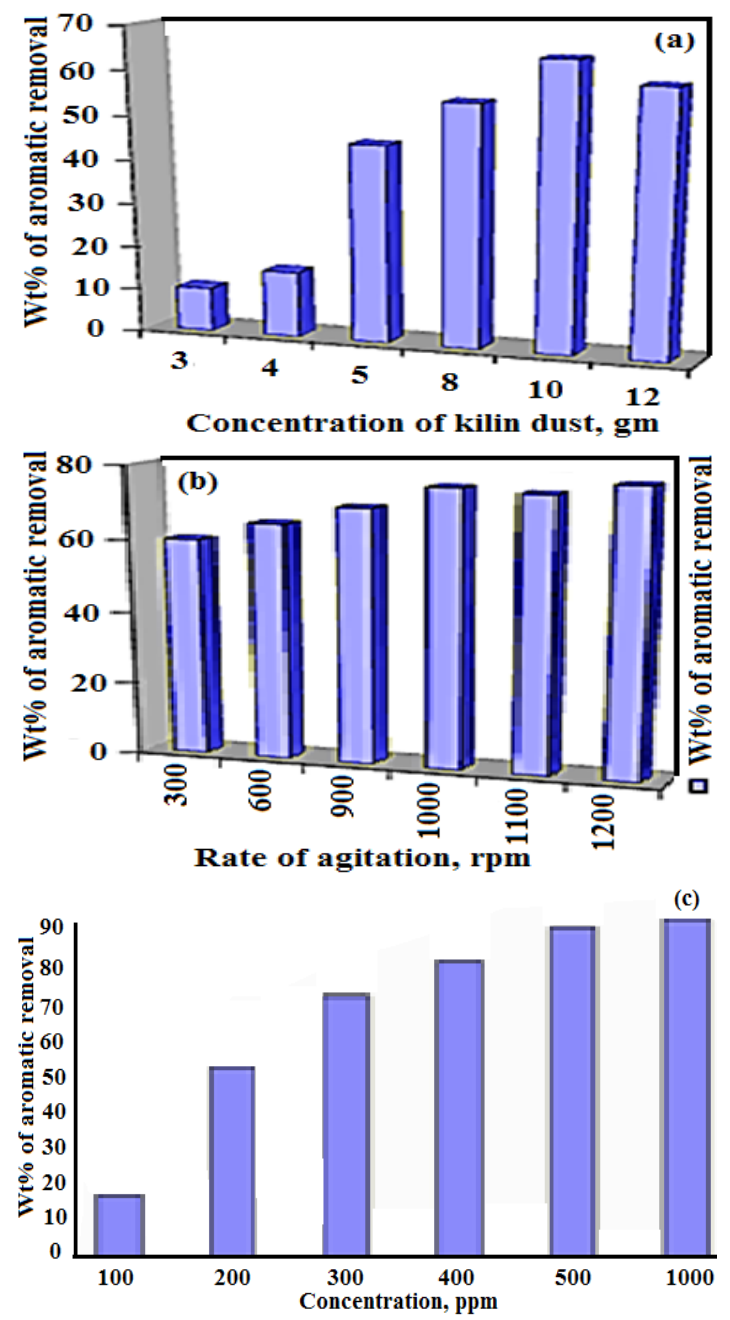

Fig. 4. (a) Effect of the concentration of kiln dust on the $w t \%$ of aromatic removal from raffinate oil; (b) Effect of the rate of agitation on the aromatic removal in raffinate at $\mathbf{5 0 0}$ ppm of the additive; (c) Effect of the concentration of the cationic surfactant on the aromatic removal from raffinate 


\section{Equilibrium Adsorption Isotherm}

To estimate the maximum capacities of kiln dust, it is necessary to know the quantity of adsorbed heavy metal and wt $\%$ of aromatic removal as a function of the adsorbate concentration in the oil raffinate according to Langmuir. The adsorption isotherms were analysed using the Langmuir equation, which has been successfully applied to many processes.

Where $\mathrm{q}\left(\mathrm{mg}^{\mathrm{g}} \mathrm{g}^{-1}\right)$ is the amount adsorbed per unit mass of kiln dust corresponding to the complete coverage of sites, q $\left(\mathrm{mg}^{-1} \mathrm{~g}^{-1}\right)$ is the equilibrium concentration of adsorbent in the solution, qm $\left(\mathrm{mg}^{-1} \mathrm{~g}^{-1}\right)$ is the adsorption capacity of the adsorbent, and $\mathrm{KI}$ $\left(\right.$ L. $\left.\mathrm{mg}^{-1}\right)$ is the Langmuir constant.

Figure 5 shows the variation in equilibrium isotherm according to the Langmuir isotherm at 500 ppm of ash content. Because of its sorption capacity, kiln dust, which is a cheap by-product adsorbent, can be used as an adsorbent to remove heavy metal complexes with aromatic cycles from nonpolar organic compounds such as raffinate oil. Nitrogen compounds in petroleum, such as pyridines, quinolines and indolines, are known as negatively affect to the oxidation stability of the base oil. The treatment of raffinate oil with kiln dust in the presence of CAS can enhance the quality of raffinate as shown in Table 5.

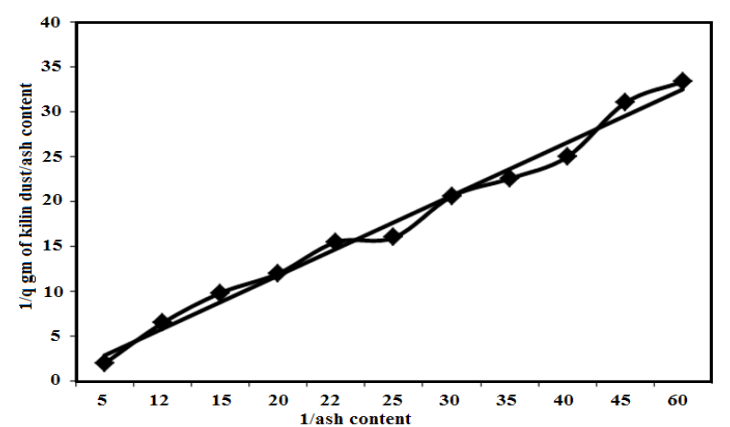

Fig. 5. Variation in the equilibrium isotherm according to the Langmuir isotherm at $\mathbf{5 0 0}$ ppm ash content
Table 5: Physicochemical properties of the raffinate after the kiln dust treatment

\begin{tabular}{lcc}
\hline Properties & Raffinate oil & Test \\
\hline Density $\left(\mathrm{g} / \mathrm{ml}\right.$ ) at $15.5^{\circ} \mathrm{C}$ & 0.8911 & D. 1298 \\
Pour point ${ }^{\circ} \mathrm{C}$ & 24 & ASTM D 97 \\
Molecular weight & 520 & GPC \\
Total paraffinic content (wr\%) & 22.4 & Urea adduction \\
Carbon residue content, wt\% & 1 & ASTM D524 \\
Total aromatic (wt $\%)$ & 6 & IP 346 \\
Nitrogen content $(w t \%)$ & 0.2 & \\
Metal, ppm & 20 & \\
\hline
\end{tabular}

\section{CONCLUSION}

In summary, the results of this study have shown that kiln dust (a by-product of cement industry) is efficient in enhancing the quality of raffinate oil. Kiln dust has a high surface area and is effective in adsorbing polar and nonpolar aromatic complexes, so kiln dust improves the quality and stability of raffinate oil. The adsorbent capacity of kiln dust was studied, and a significant enhancing degree of adsorption was found with the synthesized surfactant bromine salt of N,N-diethanol, $\mathrm{N}$-ethyllaurate-ammonium acetate.

\section{ACKNOWLEDGMENT}

This research did not receive any specific grant from funding agencies in the public, commercial, or not-for-profit sectors.

\section{Conflict Of Interest}

No conflict of interest.

\section{REFERENCES}

1. Miller G. A and Zaman M., Field.; Laboratory evaluation of cement kiln dust as soil stabilizer. Transportation Research Record., 2000, 1714, 25-32.

2. Dabrowski A.; Adsorption from theory to practice. Advances in Colloid and Interface Science., 2001, 93, 135-224.

3. ElMehbad N.; Treatment and Refining of used lubricating oil by clay with polymeric surfactants. Research Journal of Applied
Sciences, Engineering and Technology., 2017, 14(1), 7-9.

4. Alharthy A. S.; Taha R.; Almaamary F.; Effect of cement kiln dust(CKD) on mortar and concrete mixtures. Construction and Building Materials., 2003, 17, 353-360.

5. El-Shahate M.; Saraya I.; Aboul-Fetouh M. E.; Nassar H. S and Abd-El-Rahman A. M.; Journal of Materials Science and Engineering., 2011, B 1, 97-105. 
6. Elmehbad. N and Omar A. M. A. Developments of Multifunctional Additives for High Quality Lube Oil; Journal of Power and Energy Engineering., 2013, 1, 84-89.

7. Morio Y.; Nishikido N. and Matuura R. J. Colliod Interface Sci., 1974, 46, 111.

8. Morio Y.; Nishikido N. and Matuura A., J. Colloid Interface Sci., 1975, 50, 344.

9. Omar A. M. A and Abdel-Khalek N. A.; J. Chem. Eng. Data., 1999, 44, 133-137.

10. Peter Amico D.; Poling Christopher and Lineak Thomas.; U.S Patent for Cement kiln dust treatment system and method(Patent No.
9493376)., 2016.

11. Peter Amico D.; Poling Christopher, and Lineak Thomas.; US Patent for Cement kiln dust treatment system and method Patent (Patent \# 8, 876, 967), (publication No.20120272872.)., 2011.

12. EIMehbad N.; International Journal of Advanced Engineering Research and Science., 2017, 1(6), 93-97.

13. ElMehbad N.; Efficiency of N-Decyl-N-benzyl$\mathrm{N}$-methylglycine and N-Dodecyl-N-benzyl-Nmethylglycine surfactants for flow improvers and pour point depressants; Journal of Molecular Liquids., 2017, 229, 609-613. 